\title{
The effects of ethylene glycol monomethyl ether on female reproductive system in juvenile rats
}

\author{
Yoshikazu Taketa, Hiroshi Mineshima, Etsuko Ohta and Kyoko Nakano-Ito \\ Tsukuba Drug Safety, Global Drug Safety, Biopharmaceutical Assessments Core Function Unit, Eisai Co., Ltd., \\ 5-1-3 Tokodai, Tsukuba, Ibaraki 300-2635, Japan
}

(Received April 28, 2017; Accepted September 6, 2017)

\begin{abstract}
Ethylene glycol monomethyl ether (EGME), which is widely used in various industrial products, is known for adverse effects on the reproductive system in adult rats. However, the effects of EGME on reproductive development in juvenile rats have not been demonstrated. In order to investigate the effects of EGME on the female reproductive system and pubertal development in juvenile rats, EGME was administered to female Sprague Dawley rats from postnatal day 21 to 41 at a dose level of $0,50,100$, or $300 \mathrm{mg} / \mathrm{kg}$. The animals were examined for general condition, body weight, vaginal opening (VO), estrous cyclicity, and histopathology of reproductive organs. EGME treatment resulted in a prolonged estrous cycle interval characterized by persistent diestrus at $50 \mathrm{mg} / \mathrm{kg}$ without effects on body weight, timing of VO, or histology of the reproductive organs. EGME at $100 \mathrm{mg} / \mathrm{kg}$ induced decreases in body weight gain, a delay of VO, and irregular estrous cycle with absence of corpora lutea and hypertrophy of uterine epithelium indicating disturbance of the ovulatory process associated with hormonal effect. At $300 \mathrm{mg} / \mathrm{kg}$, there was significant delay of puberty due to severe growth retardation. The present results revealed that irregular estrous cycle is a first indicator of the effects of EGME on the female reproductive system in juvenile rats, with delayed pubertal onset and ovulatory process disturbance at a higher dose.
\end{abstract}

Key words: Estrous cycle, Ethylene glycol monomethyl ether, Female pubertal development, Juvenile rats, Reproductive organs

\section{INTRODUCTION}

In recent years, there has been growing interest in the possible health threat posed by chemical substances in the environment and industrial products that interfere with reproductive function. The adverse effects of these substances on pubertal development have been of increasing concern (Fisher and Eugster, 2014; Schoeters et al., 2008). For instance, chlorotriazine herbicides such as atrazine and simazine have been reported to disrupt pubertal development; accompanied by a delayed onset of puberty or irregular estrous cyclicity (Davis et al., 2011; Zorrilla et al., 2010).

Ethylene glycol monomethyl ether (EGME), which is widely used as a solvent in various industrial products such as detergents, printing inks, varnishes and textile dyes, adversely affects both the male and female reproductive systems (Johanson, 2000; Welsch, 2005). The reproductive toxicity of EGME in adult female animals includes reduced fertility, increased number of dead and resorbed fetuses, decreased postnatal survival and increased incidences of skeletal variations and malformations of the extremities and visceral organs (Johanson, 2000; Welsch, 2005). In sexually mature female rats, EGME and its active metabolite, 2-methoxy acetic acid, disrupts the hypothalamic-pituitary-gonadal (HPG) axis and induces irregular estrous cyclicity, associated with hypersecretion of progesterone (P4) from luteal cells and an increase in blood prolactin (PRL) level (Almekinder et al., 1997; Davis et al., 1997; Taketa et al., 2011b). Repeated administration of EGME resulted histologically in luteal hypertrophy in rats (Davis et al., 1997; Taketa et al., 2011a, 2013), which was consistent with hypersecretion of $\mathrm{P} 4$.

Despite the well-known effects of EGME on the reproductive system in adult animals, its effects on reproductive development have not been fully evaluated in juvenile rats. The present study investigated the effects of EGME on the female reproductive system and early pubertal development in the juvenile rats.

Correspondence: Yoshikazu Taketa (E-mail: y-taketa@hhc.eisai.co.jp) 


\section{Y. Taketa et al.}

\section{MATERIALS AND METHODS}

\section{Animals}

Seven pregnant female Sprague Dawley (SD) rats were purchased from CLEA Japan, Inc. (Tokyo, Japan) and shipped to arrive on gestation day 13. Upon arrival, the rats were housed one per cage and maintained at $20-26^{\circ} \mathrm{C}$ and a relative humidity of $48-69 \%$ with a 12-hr light cycle (on 07:00 hr, off 19:00 hr). Commercial rodent chow (CRF-1; Oriental Yeast Co., Ltd., Tokyo, Japan) and water were provided ad libitum. The day of birth was designated postnatal day (PND) 0. On PND 6 or 7 , the litters were standardized to 10 pups each to maximize uniformity in postnatal growth rates. On PND 21, all female pups were weaned and were assigned so that treatment groups had similar body weight means and variances. Littermates were equally distributed among the treatment groups. After assignment, animals were singly housed throughout treatment. The study protocol was approved by the Laboratory Animal Care and Use Committee and was performed in compliance with the Laboratory Animal Policy of Eisai Co., Ltd.

\section{Chemicals}

EGME was purchased from Wako Pure Chemical Industries, Ltd. (Osaka, Japan), and was dissolved in water for injection for a dose volume of $5 \mathrm{~mL} / \mathrm{kg}$ body weight.

\section{Experimental design}

The experimental design including dosing period was modified according to the Endocrine Distruptor Screening and Testing Advisory Committee (EDSTAC) Tier I Female Pubertal Screening Protocol (Goldman et al., 2000). EGME was orally administered to juvenile female rats (9 animals/group) for 21 days, at a dose level of 50, 100 , or $300 \mathrm{mg} / \mathrm{kg}$ from PND 21 to 41 . Effective doses on the female reproductive organs were selected based on the relevant literature for the mature female rat (Davis et al., 1997; Dodo et al., 2009; Taketa et al., 2011a). A control group (8 animals) received an equivalent volume of water for injection. The animals were observed daily for general condition, body weight, vaginal opening (VO), and estrous cycle with vaginal smears from VO to PND 41. On the next day, following the last treatment, animals were euthanized by decapitation. The ovaries, vagina, and uterus were fixed in 10\% neutral-buffered formalin and embedded in paraffin. Both sides of each ovary were transversely dissected to examine their maximum areas. The paraffin sections were stained with hematoxylin and eosin and histologically examined. Histological evaluation and interpretation of the immature reproductive organs were based on the well-established descriptions in literature for postnatal reproductive organ development (Picut et al., 2015, 2016).

\section{Statistical analysis}

Following Bartlett's test, variance in data for body weight, age of VO, age of first estrus, and body weight at VO were compared between treatment and control groups by one-way analysis of variance (ANOVA). When statistically significant differences were detected, Dunnett's multiple comparison test was employed for comparison between the control group and treatment groups. In these tests, the level of significance was set at 0.05 or 0.01 .

\section{RESULTS}

\section{Body weight and general toxicity}

Significantly lower mean body weight was noted at 100 and $300 \mathrm{mg} / \mathrm{kg}$ compared to controls from PND 27 and 23, respectively, through to the end of the dosing period (PND 41) (Fig. 1). The reduction was $-11.6 \%$ and $-37.4 \%$, respectively. There was no difference in body weight change between the $50 \mathrm{mg} / \mathrm{kg}$ and control groups. No clinical abnormality was observed in any of the treated groups.

\section{Parameters for onset of puberty}

All animals showed VO in control and $50 \mathrm{mg} / \mathrm{kg}$ groups at approximately PND 30 (Table 1). VO was not

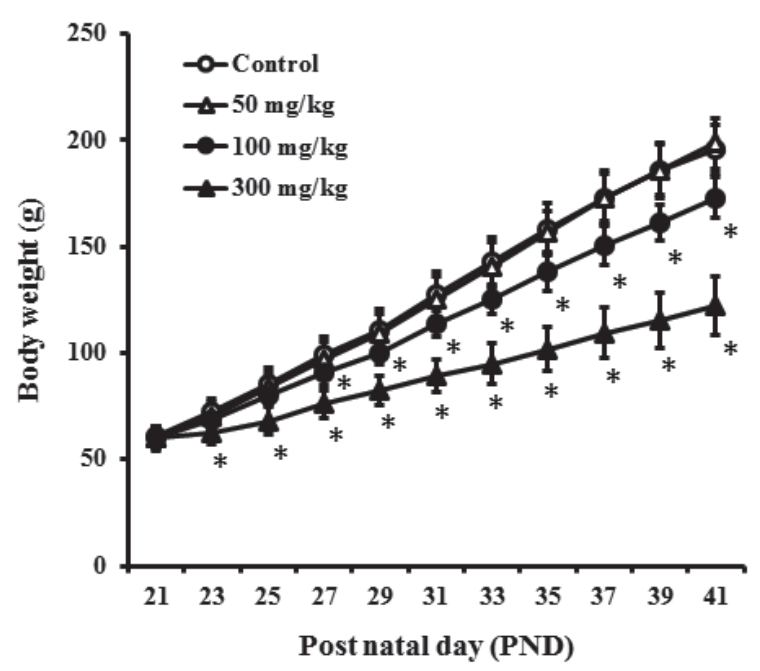

Fig. 1. Sequential body weight changes during treatment period of PND 21 to 41. Data showed as mean \pm S.D. Asterisk $(p<0.05)$ indicates significant difference between the EGME-treated group and control group. 
Effect of EGME on juvenile female rats

observed until termination of the study (PND 42) in 1 out of 9 (Animal No. 9) and 6 out of 9 females (Animal Nos. 4 to 9) at 100 and $300 \mathrm{mg} / \mathrm{kg}$, respectively (Table 1). VO was significantly delayed at 100 (2.9 days) and 300 (9.2 days) $\mathrm{mg} / \mathrm{kg}$ compared to controls, but no significant difference was noted and considered no change at $50 \mathrm{mg} / \mathrm{kg}$ (Table 1). The age of first estrus tended to be delayed at $100 \mathrm{mg} / \mathrm{kg}$, but there was no statistically significant difference compared to controls. At $300 \mathrm{mg} / \mathrm{kg}$, there was no animal which showed first estrus. Body weights at the time of VO were similar among the groups including control and treated groups up to $300 \mathrm{mg} / \mathrm{kg}$ even though the timing of $\mathrm{VO}$ was delayed.

\section{Estrous cyclicity}

In the control group, all animals showed normal 4- or 5-day estrous cycles after the first estrus (Fig. 2). Irregular estrous cycle, characterized by prolonged estrous interval (6 days or longer) with persistent diestrus (continued 4 days or longer) was observed at $50 \mathrm{mg} / \mathrm{kg}$ (Table 1 and Fig. 2). At $100 \mathrm{mg} / \mathrm{kg}$, no animals showed normal cycles, and most of the animals had persistent diestrus or estrus (continued for 3 days or longer) (Table 1 and Fig. 2). At $300 \mathrm{mg} / \mathrm{kg}$, no sign of estrus was observed after VO through to the end of treatment period.

\section{Histological changes in the female reproductive organs (Table 2)}

The ovaries in control and $50 \mathrm{mg} / \mathrm{kg}$ groups contained various stages and sizes of follicles and corpora lutea (CL) (Fig. 3a). In 1 animal at $100 \mathrm{mg} / \mathrm{kg}$ (Animal No. 1), no CL was observed but various stages of follicles were present (absent, CL) (Fig. 3b). In 2 females including the animal which did not show VO (Animal Nos. 3 and 9), ovary was immature, and predominantly occupied by small follicles without the presence of CL. In the other 7 females, the ovary was histologically normal. At $300 \mathrm{mg} / \mathrm{kg}$, ovary was immature in all animals, including in 3 females which had shown VO (Animal Nos. 1, 2, and 3) (Fig. 3c).

In the uterus of 2 animals without CL at $100 \mathrm{mg} / \mathrm{kg}$ (Animal Nos. 1 and 3), the luminal epithelium was hypertrophic, i.e. tall columnar cells with an increase in cytoplasm/nuclear ratio compared to controls (Fig. 4). One animal at $100 \mathrm{mg} / \mathrm{kg}$ (Animal No. 9) and 8 animals at $300 \mathrm{mg} / \mathrm{kg}$ (Animal Nos. 1 to 8 ) had immature uterus which was characterized by compact stroma, small number of glands, and thin layers of muscularis. Vaginal epithelium was also immature and composed of several cuboidal epithelial cells and an upper layer of mucinous cells in 2 animals at $100 \mathrm{mg} / \mathrm{kg}$ (Animal Nos. 4 and 9) and 8 animals at $300 \mathrm{mg} / \mathrm{kg}$ (Animal Nos. 1 to 8 ).

\section{DISCUSSION}

Estrous cyclicity was the first endpoint affected in EGME-induced effects on the female reproductive system in the rat. In mature female rats, EGME prolongs estrous interval with persistent diestrus and decreased frequency of estrus accompanied by increases in serum P4 and

Table 1. Parameters for onset of puberty and estrous cycle.

\begin{tabular}{|c|c|c|c|c|}
\hline & Control & EGME & EGME & EGME \\
\hline & & $50 \mathrm{mg} / \mathrm{kg}$ & $100 \mathrm{mg} / \mathrm{kg}$ & $300 \mathrm{mg} / \mathrm{kg}$ \\
\hline Number of animals examined & 8 & 9 & 9 & 9 \\
\hline \multicolumn{5}{|l|}{ Number of animals showed VO on PND 42} \\
\hline & $8(100 \%)$ & $9(100 \%)$ & $8(88.9 \%)$ & $3(33.3 \%)$ \\
\hline \multicolumn{5}{|l|}{ Age of vaginal opening (VO) } \\
\hline$(\mathrm{PND})^{\#}$ & $29.5 \pm 0.9$ & $30.7 \pm 0.7$ & $32.4 \pm 0.7^{*}$ & $38.7 \pm 3.1^{*}$ \\
\hline \multicolumn{5}{|l|}{ Age of first estrus } \\
\hline$(\mathrm{PND})^{\#}$ & $31.8 \pm 2.2$ & $33.4 \pm 2.7$ & $34.0 \pm 3.2$ & $\mathrm{NC}$ \\
\hline \multicolumn{5}{|l|}{ Body weight at $\mathrm{VO}$} \\
\hline$(\mathrm{g})^{\#}$ & $115.4 \pm 9.7$ & $122.3 \pm 7.4$ & $122.7 \pm 5.6$ & $110.9 \pm 12.0$ \\
\hline \multicolumn{5}{|c|}{ Number of animals showed prolonged estrous cycle interval after first estrus } \\
\hline & 0 & $6(66.7 \%)$ & $2(25 \%)$ & $\mathrm{NC}$ \\
\hline \multicolumn{5}{|c|}{ Number of animals showed persistent estrus after first estrus } \\
\hline & 0 & 0 & $3(37.5 \%)$ & $\mathrm{NC}$ \\
\hline
\end{tabular}

\# Data showed mean \pm S.D.

$* \mathrm{P}<0.01$, Significant difference compared to control group

NC: Not calculated since no animals showed first estrus

Prolonged estrous cycle interval: 6 days or longer interval between cycles

Persistent estrus: Estrus stage continued 3 days or longer 


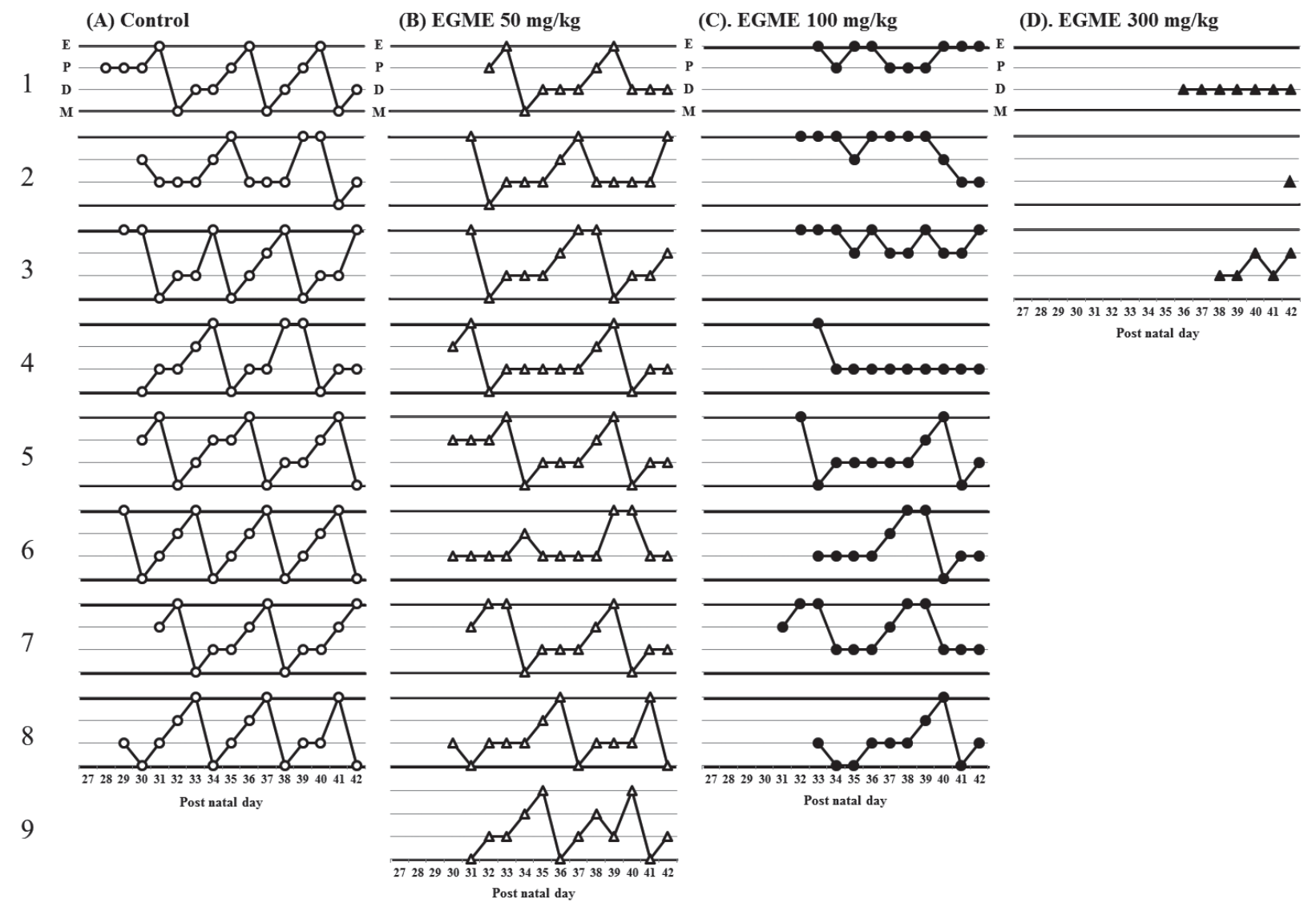

Fig. 2. Estrous cycle of each animal after vaginal opening. A, control group; B, EGME $50 \mathrm{mg} / \mathrm{kg}$ group; C, EGME $100 \mathrm{mg} / \mathrm{kg}$ group; D, EGME $300 \mathrm{mg} / \mathrm{kg}$ group. Each plot exhibits the stage of estrous cycle (E, estrus; P, proestrus; D, diestrus; M, metestrus).

Table 2. Histopathological findings of the female reproductive organs.

\begin{tabular}{lccccc} 
& & Control & EGME & EGME & EGME \\
\cline { 3 - 6 } & & & $50 \mathrm{mg} / \mathrm{kg}$ & $100 \mathrm{mg} / \mathrm{kg}$ & $300 \mathrm{mg} / \mathrm{kg}$ \\
\hline Number of animals examined & & & 9 & 9 & 9 \\
\hline Ovaries & $\mathrm{p}$ & 0 & 0 & 1 & 0 \\
$\quad$ Absent, corpora lutea & $\mathrm{p}$ & 0 & 0 & 2 & 9 \\
$\quad$ Immature & $1+$ & 0 & 0 & 2 & 0 \\
Uterus & $\mathrm{p}$ & 0 & 0 & 1 & 8 \\
$\quad$ Hypertrophy, luminal epithelium & $\mathrm{p}$ & 0 & 0 & 2 & 8 \\
$\quad$ Immature & & & & \\
Vagina & & &
\end{tabular}

Grade: 1+, slight; 2+, moderate; 3+, marked; p, present

PRL levels (Dodo et al., 2009; Taketa et al., 2011b). The prolonged estrous interval noted in the present study at low dose of $50 \mathrm{mg} / \mathrm{kg}$ in pubertal rats was similar to mature female rats; this change was considered to have possibly developed through disruption of the HPG axis during the juvenile to pubertal stages.

At $100 \mathrm{mg} / \mathrm{kg}$, the effects of EGME on the female reproductive system was more apparent including per- 
Effect of EGME on juvenile female rats
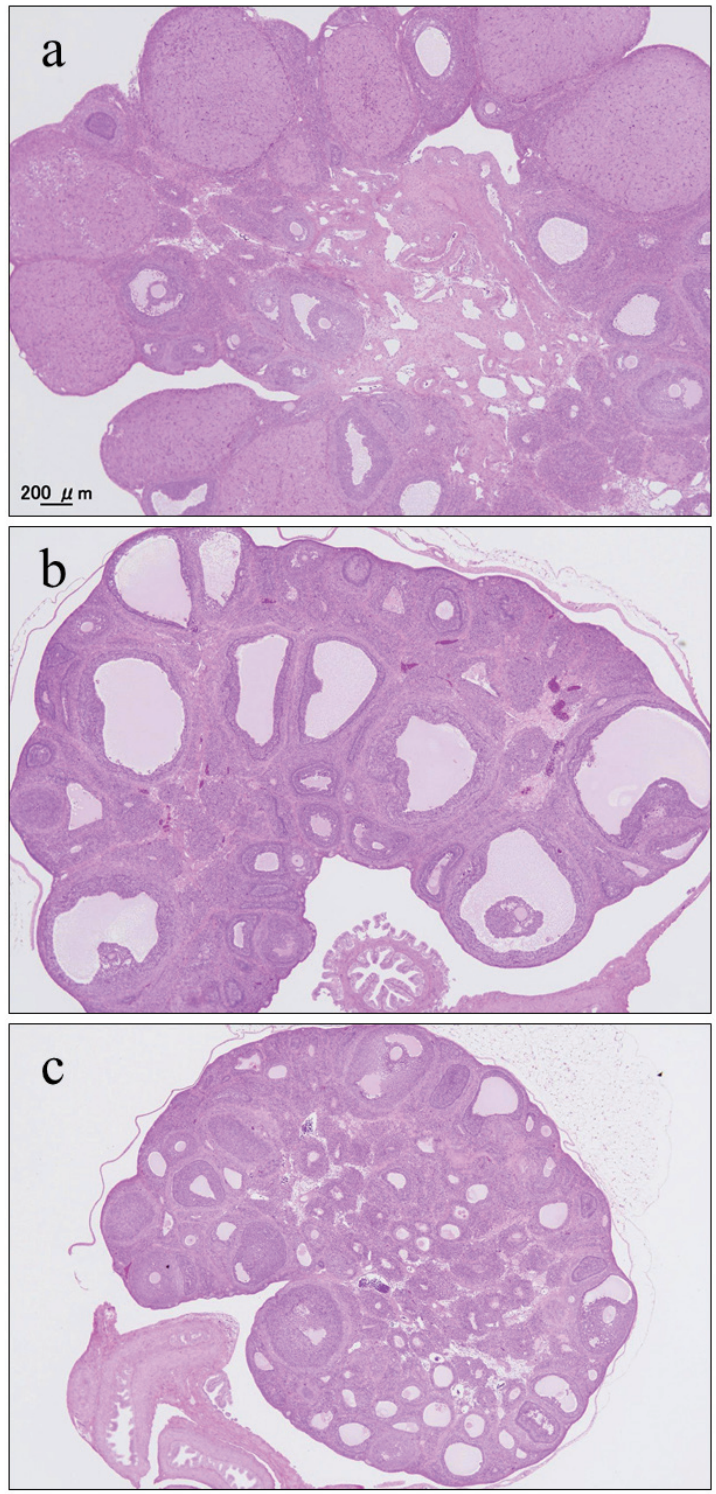

Fig. 3. Representative histological pictures of the ovaries in the control (a, normal), EGME $100 \mathrm{mg} / \mathrm{kg}$ (b, absent of corpora lutea), and EGME $300 \mathrm{mg} / \mathrm{kg}$ (c, immature) groups. Hematoxylin and eosin staining. Bar represent $200 \mu \mathrm{m}$.

sistent estrus in addition to persistent diestrus, hypertrophy of uterine epithelium, and absence of CL in the ovary. Although decreases in body weight gain by food restriction are known to induce persistent diestrus and decreased number of CL (Chapin et al., 1993; Hayashi et al., 2013), the characteristics of persistent estrus and hypertrophy of uterine epithelium are not commonly observed as secondary changes due to the effect
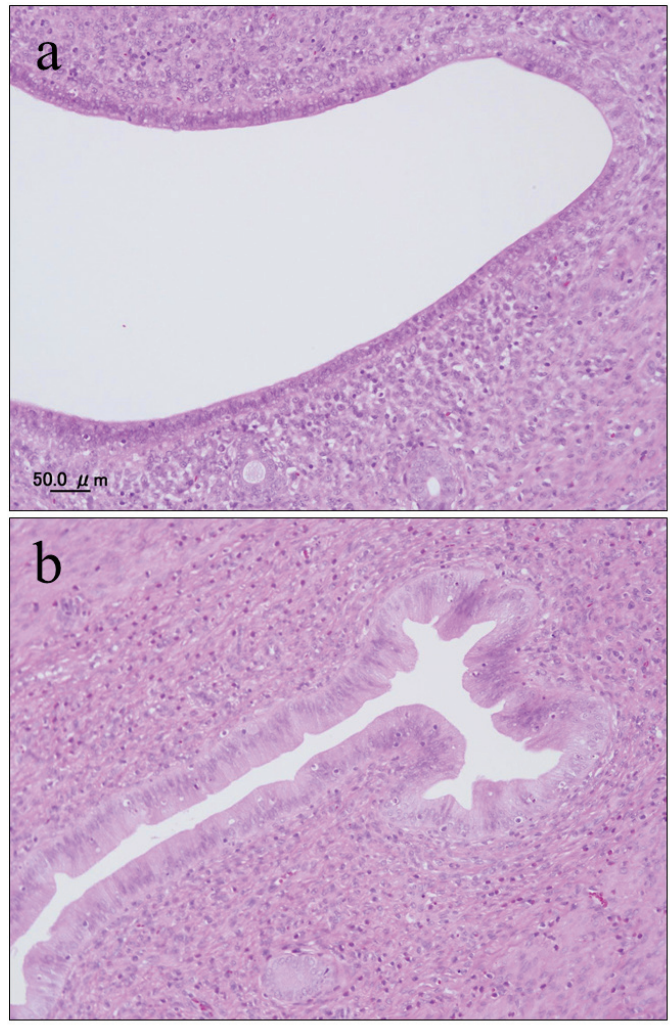

Fig. 4. Representative histological pictures of the uterus in the control (a, normal) and EGME $100 \mathrm{mg} / \mathrm{kg}$ (b, hypertrophy of luminal epithelium) groups. Hematoxylin and eosin staining. Bar represent $50 \mu \mathrm{m}$.

on body weight and were likely to be related to the primary effects of EGME on these tissues. Persistent estrus and tall columnar endometrial epithelium are characteristic of prolonged tonic estradiol $\left(\mathrm{E}_{2}\right)$ secretion or increased $\mathrm{E}_{2} / \mathrm{P} 4$ ratio (Westwood, 2008). The absence of CL indicated that there had been no ovulation for a certain period of time. These findings indicate that EGME at $100 \mathrm{mg} / \mathrm{kg}$ is likely to have effects on the ovulatory process which may be associated with prolonged tonic blood estrogen levels. In terms of the persistent diestrus at $100 \mathrm{mg} / \mathrm{kg}$, the change was observed from low dose and in mature animals without any effect on body weight (Dodo et al., 2009). It appears that the persistent diestrus at this dose level also can be considered a primary effect of EGME, although this change could be complicated by the secondary effect of decreases in body weight gain. The individual variation in the changes of estrous cyclicity, persistent estrus or diestrus, was considered to be due to the difference of the sensitivity to the effect of EGME in each animal. Regarding the delay of puberty onset at $100 \mathrm{mg} / \mathrm{kg}$, 
GnRH agonists or antagonists, dopamine receptor agonists, or estrogen antagonists are known to induce the delay of VO (Goldman et al., 2000). Considering this report, EGME possibly disrupts the HPG axis during the juvenile to peripubertal periods such as increases in gonadotropin or decreases in gonadotropin, PRL, or $\mathrm{E}_{2}$, which results in the delay of VO. Although several studies have shown that the reductions in daily food consumption and associated lower body weight of up to $10 \%$ do not alter the endpoints in the pubertal assays (Chapin et al., 1993; Laws et al., 2007), the body weight at VO was similar to that in controls in this study. It was suggested the effect of growth retardation should also have some contribution to the present delay in sexual maturation. On the other hand, CL in ovaries, when present, showed no obvious changes in this study. In mature female rats, the target tissue of EGME in the ovary was CL, which was characterized by luteal cell hypertrophy associated with increases in serum P4 and PRL levels (Taketa et al., 2011b). During the juvenile to pubertal stages, HPG axis are central to the dramatic neuroendocrine changes in the process of maturation, including changes in $\mathrm{E}_{2}$ positive/negative feedback system and gonadotropin and their receptor levels (Picut et al., 2015). The difference in the effects of EGME among juvenile, pubertal, and mature rats is possibly due to the differential effects of EGME on the HPG axis or the difference in the sensitivity or regulation of the hormonal effects of $\mathrm{E}_{2}$ or $\mathrm{P} 4$ on the reproductive organs during sexual maturation, with the complication of secondary effect of growth retardation and delay in the onset of puberty (Ohta et al., 1996; Picut et al., 2015; Sar and Welsch, 1999).

The highest dose, at $300 \mathrm{mg} / \mathrm{kg}$ of EGME, showed severe growth retardation with more than $30 \%$ lower body weight compared to controls as well as significant delay in puberty onset, and disruption of estrous cycle. This was in line with histology, which indicated the animals still had immature reproductive organs even at the end of dosing. Severe body weight loss is reported to correlate with the onset of puberty in rodents (Odum et al., 2004). On the other hand, the body weight at the timing of VO was similar across groups; the present delay in sexual maturation seems to be due to growth retardation at 300 $\mathrm{mg} / \mathrm{kg}$. Considering the various secondary factors related to marked low body weight and poor physical condition, the discussion of primary toxicity of EGME should be limited up to the dose of $100 \mathrm{mg} / \mathrm{kg}$.

The present study examined the effects of EGME administered during the juvenile to pubertal stages, but without assessment of hormonal changes. Further investigation including hormonal measurement is needed to clarify effects of EGME during the pubertal development, as well as to differentiate between the direct effects of EGME and the nonspecific indirect adverse effects on female reproductive maturation.

In conclusion, EGME exposure in female rats during the juvenile to pubertal stages resulted in prolonged diestrus after the onset of puberty at $50 \mathrm{mg} / \mathrm{kg}$, and a delay in the onset of puberty and prolonged estrus with interference with the ovulatory process at $100 \mathrm{mg} / \mathrm{kg}$. To our knowledge, this is the first report evaluating the effects of EGME on the juvenile female reproductive system in rats. We believe this would be an additional contribution to pediatric human risk assessment of chemicals.

\section{ACKNOWLEDGMENTS}

I deeply thank Ms. Michiyo Shimada, Mr. Takaya Shimomura, Ms. Sachiko Tsukada, Mr. Toshio Imade, and Mr. Shota Yokota (Sunplanet Co., Ltd.) for their excellent technical assistance. I also appreciate Ms. Kathy Vanderhoof (Eisai Inc.) for her critical review and helpful comments.

Conflict of interest---- The authors declare that there is no conflict of interest.

\section{REFERENCES}

Almekinder, J.L., Lennard, D.E., Walme, D.K. and Davi, B.J. (1997): Toxicity of methoxyacetic acid in cultured human luteal cells. Fundam. Appl. Toxicol., 38, 191-194.

Chapin, R.E., Gulati, D.K., Barnes, L.H. and Teague, J.L. (1993): The effects of feed restriction on reproductive function in Sprague-Dawley rats. Fundam. Appl. Toxicol., 20, 23-29.

Davis, B.J., Almekinder, J.L., Flagler, N., Travlos, G., Wilson, R. and Maronpot, R.R. (1997): Ovarian luteal cell toxicity of ethylene glycol monomethyl ether and methoxy acetic acid in vivo and in vitro. Toxicol. Appl. Pharmacol., 142, 328-337.

Davis, L.K., Murr, A.S., Best, D.S., Fraites, M.J., Zorrilla, L.M., Narotsky, M.G., Stoker, T.E., Goldman, J.M. and Cooper, R.L. (2011): The effects of prenatal exposure to atrazine on pubertal and postnatal reproductive indices in the female rat. Reprod. Toxicol., 32, 43-51.

Dodo, T., Taketa, Y., Sugiyama, M., Inomata, A., Sonoda, J., Okuda, Y., Mineshima, H., Hosokawa, S. and Aoki, T. (2009): Collaborative work on evaluation of ovarian toxicity. 11) Two- or fourweek repeated-dose studies and fertility study of ethylene glycol monomethyl ether in female rats. J. Toxicol. Sci., 34, SP121128.

Fisher, M.M. and Eugster, E.A. (2014): What is in our environment that effects puberty? Reprod. Toxicol., 44, 7-14.

Goldman, J.M., Laws, S.C., Balchak, S.K., Cooper, R.L. and Kavlock, R.J. (2000): Endocrine-disrupting chemicals: prepubertal exposures and effects on sexual maturation and thyroid activity in the female rat. A focus on the EDSTAC recommendations. Crit. Rev. Toxicol., 30, 135-196. 
Effect of EGME on juvenile female rats

Hayashi, S., Taketa, Y., Inoue, K., Takahashi, M., Matsuo, S., Irie, K., Watanabe, G. and Yoshida, M. (2013): Effects of pyperonyl butoxide on the female reproductive tract in rats. J. Toxicol. Sci., 38, 891-902.

Johanson, G. (2000): Toxicity review of ethylene glycol monomethyl ether and its acetate ester. Crit. Rev. Toxicol., 30, 307-345.

Laws, S.C., Stoker, T.E., Ferrell, J.M., Hotchkiss, M.G. and Cooper, R.L. (2007): Effects of altered food intake during pubertal development in male and female Wistar rats. Toxicol. Sci., 100, 194202.

Odum, J., Tinwell, H., Tobin, G. and Ashby, J. (2004): Cumulative dietary energy intake determines the onset of puberty in female rats. Environ. Health. Perspect., 112, 1472-1480.

Ohta, Y., Fukazawa, Y., Sato, T., Suzuki, A., Nishimura, N. and Iguchi, T. (1996): Effect of estrogen on ontogenic expression of progesterone and estrogen receptors in rat uterus. Zoolog. Sci., 13, 143-149.

Picut, C.A., Dixon, D., Simons, M.L., Stump, D.G., Parker, G.A. and Remick, A.K. (2015): Postnatal ovary development in the rat: morphologic study and correlation of morphology to neuroendocrine parameters. Toxicol. Pathol., 43, 343-353.

Picut, C.A. and Remick, A.K. (2016): Female Reproductive System. In Atlas of Histology of the Juvenile Rat (Parker, G.A., Picut, C.A. ed.), pp. 203-226, Academic Press, London.

Sar, M. and Welsch, F. (1999): Differential expression of estrogen receptor- $\beta$ and estrogen receptor- $\alpha$ in the rat ovary. Endocrinology, 140, 963-971.

Schoeters, G., Den, Hond, E., Dhooge, W., van Larebeke, N. and
Leijs, M. (2008): Endocrine disruptors and abnormalities of pubertal development. Basic Clin. Pharmacol. Toxicol., 102, 168-175.

Taketa, Y., Inomata, A., Hosokawa, S., Sonoda, J., Hayakawa, K., Nakano, K., Momozawa, Y., Yamate, J., Yoshida, M., Aoki, T., and Tsukidate, K. (2011a): Histopathological characteristics of luteal hypertrophy induced by ethylene glycol monomethyl ether with a comparison to normal luteal morphology in rats. Toxicol. Pathol., 39, 372-380.

Taketa, Y., Inoue, K., Takahashi, M., Yamate, J. and Yoshida, M. (2013): Differential morphological effects in rat corpora lutea among ethylene glycol monomethyl ether, atrazine, and bromocriptine. Toxicol. Pathol., 41, 736-743.

Taketa, Y., Yoshida, M., Inoue, K., Takahashi, M., Sakamoto, Y., Watanabe, G., Taya, K., Yamate, J. and Nishikawa, A. (2011b): Differential stimulation pathways of progesterone secretion from newly formed corpora lutea in rats treated with ethylene glycol monomethyl ether, sulpiride, or atrazine. Toxicol. Sci., 121, 267278.

Welsch, F. (2005): The mechanism of ethylene glycol ether reproductive and developmental toxicity and evidence for adverse effects in humans. Toxicol. Lett., 156, 13-28.

Westwood, F.R. (2008): The female rat reproductive cycle: a practical histological guide to staging. Toxicol. Pathol., 36, 375-384.

Zorrilla, L.M., Gibson, E.K. and Stoker, T.E. (2010): The effects of simazine, a chlorotriazine herbicide, on pubertal development in the female Wistar rat. Reprod. Toxicol., 29, 393-400. 